\title{
A Cognitive Interpretation for Non-Past Uses of the Simple Past Tense
}

\author{
Jin Liu \\ School of Foreign Languages, Guizhou Normal University, Guiyang, China \\ Email: wyxylj@163.com
}

Received 22 July 2016; accepted 27 August 2016; published 30 August 2016

Copyright (C) 2016 by author and Scientific Research Publishing Inc.

This work is licensed under the Creative Commons Attribution International License (CC BY). http://creativecommons.org/licenses/by/4.0/

(c) (i) Open Access

\begin{abstract}
The non-typical uses of the simple past tense are rather popular and reflect people's cognitive thinking. These usages are largely embodied in the counterfactual past, the indirect speech and the pragmatic softening. This research attempts to interpret these non-typical usages of the simple past tense employing the mental space theory. A cognitive interpretation of English simple past tense can better understand the cognitive mechanisms of counterfactual events.
\end{abstract}

\section{Keywords}

The Simple Past Tense, Non-Past Uses, Mental Space Theory

\section{Introduction}

It is generally accepted that the simple past tense mainly represents the state or action of the past event. Besides the expression of the past event, the simple past tense can also convey non-past time or non-temporal meanings. For instance, it can also refer to the events of habitual past and counterfactual past. Meanwhile, it is widely used in indirect speech and pragmatic softener. What's motivation for the simple past tense expressing non-past events or non-temporal meanings? What is the cognitive mechanism behind this phenomenon? This research attempts to employ the mental space theory to explore several kinds of non-past usages of the simple past tense. Recent research demonstrates that numerous scholars look upon this phenomenon as the metaphorical means of language and the prototypical usage. It is very delighted that there have been part of researchers addressing to the simple past tense from the conceptual blending theory or mental space theory, but for its non-past uses, there are few research from the perspective of mental space theory. 


\section{Review of the Simple Past Tense}

\subsection{Typical Uses of the Simple Past Tense}

Different researchers have various definitions about the simple past tense, however, they are unanimous that it regards a kind of verbal form of time with an event or state occurring or existing before the present moment [1]. The central patterns of usage of the simple past tense represent a event or state of what's happened making use of the present time as the reference point. The typical usages of the simple past tense have been addressed from various aspects. Taylor (2001) [2] points out that the past tense indicates an event or state at some point or period prior to the moment of speaking or writing. Comire (1985) [3] claims that the past tense is built on a situation in time prior to the present moment and proposes that the way the past time represents is appropriate for explanation about absolute tense, but inadequate explanations for relative tense. Leech (1987) [4] claims that the past tense should be a kind of event taking place before the present moment. So perhaps as it stands, the most common characteristics of the past tense is an indication of a situation at a time before the speaking time In other word, the past tense is considered to be a grammatical form essentially, indicating a temporal location in relation to the speech time.

On the whole, the past tense can be described as conveying the past event or the past information. Tense becomes a grammatical category and reflects through the verb form. Speakers adopt the verb form to represent the time distinctions. The past tense primarily expresses past events or states. The past events or states have become the basic or typical usages of the past tense. From the point of this one angle, only the typical meaning is elaborated back and forth and other meanings of the past tense are ignored and are ranked the least important place.

\subsection{Non-Typical Uses of the Simple Past Tense}

We can see from a large number of linguistic examples that the past tense is not only utilized to indicate the past time, but also bears some other non-typical usages differing from those typical usages. The past tense, like expressing politeness, giving advices, indicating the counterfactual facts or functioning as pragmatic softeners, etc. Apart from expressing the past event, the past tense can also be employed to denote the present or future event.

Langacker (2004) [5] proposes that grammar is conceptualization and knowledge of language emerges from language use in term of cognitive grammar. He claims that the structure of grammar is the interplay between conceptualization and the object of conceptualization. Sweetser (1990) [6] adopts the metaphorical view of language and assumes that the mental space concerning the physical experiences will be crucial influence upon the formation and development of polysemy. And cognate words in the related languages locate in the mutual linking network. Taylor (2001) [2] considers the past tense as a polysemous category, namely a property of lexical category. Other categories-morphosyntactic categories of tense and aspect, syntactic categories of sentence types, prosodic categories like intonation contours probably exhibit likewise a bunch of related with hierarchy meanings, thus boosting abundant instances of polysemy. Fauconnier (1997) [7] points out that the temporal points of different events and the reference points can signify various mental spaces. In his opinion, the tense can be counted as the driver of choice for building means of keeping track of time through much longer extending of thought and discourse. Langacker (2004) [5] innovates the term "grounding" and describes the usages of the present tense and the past tense. He assumes that the present tense and the past tense of English involve in fundamental semantic characterization pertaining to epistemic distance. And these semantic characteristics are prototypically construed with reference to time-line model.

Obviously, much research has been addressed to the non-past uses of the past tense from a cognitive perspective. However, these studies on the non-past uses of the simple past tense mainly contribute to the metaphorical uses or the polysemy device.

\section{The Mental Space Theory}

Mental space theory was first proposed by Fauconnier in the 1980s. This theory deals with the process of language understanding and production, achieving pragmatic functions by various means to some degree. It also provides a new approach with some non-typical linguistic phenomena.

\subsection{The Connotation of Mental Space Theory}

The mental space theory was first proposed by Fauconnier and further developed by Dins more (1991) [8]. Fau- 
connier (1997) [7] defines mental spaces as domains of back stage cognition, namely, the abstract mental constructs are built on the basis of general scenarios. According to their statement, mental spaces are not innate in linguistic forms and in semantic structures, but a temporal container connecting with total information about a certain domain of information. The basic tenets of mental space are gradually constructed and connected and new mental spaces are built under the guidance of grammar, context and culture in term of speakers think and talk.

Mental space acts as a bridge connecting the network structure of language can better recognize the realization mechanisms of discourse and construction of language. Four spaces can be built in the process of language cognition, that is base space (the reality space that is a starting point for the construction to which it is always possible to return), viewpoint space (the one from which other spaces are being built), focus space (the one on which attention is currently focused) and event space. The dynamic configuration of four spaces makes the movement of discourse become a whole framework. The mental space expounds the process of meaning emerging and construing, and likewise builds up a theoretical basis for dynamic discourse analysis. In a word, the conveying and adaptation of discourse present a mutual process that forms the framework of projects or crosses mental space and realizes the discourse mental representation.

\subsection{Some Basic Tenets of the Mental Space Theory}

The mental space theory has been paid much attention, which has brought about its great development and its research areas are enlarged gradually. The main function of language structure rests with language use or gives rise to different information approachability. Nevertheless, getting to know the usage of language is an important cognitive means of human beings. Generally speaking, understanding of some basic tenets of mental space theory can better achieve its pragmatic effects in different language contexts.

\subsubsection{Space Builder}

Space builder acts as one of the triggers of mental space, which similarly covering grammatical markers and pragmatic message [9]. In the simple past tense, time adverbials like yesterday, last night, three years ago and connectives like if are space builders. These space builder words all contain certain grammatical markers and also convey much pragmatic message because they drive speakers across a bridge to approaching another mental space. Most of the time, speakers can achieve certain mental preparation while accepting new information. In addition, speakers can build their own imaginative space in term of the space builder words and their perspective. A construction does have its meaning only when speakers entitle to it. Only when the construction is put into a complete discourse and concrete context, does it has its potential meaning. Space builder can give these potential meaning unfold multiple constructional networks and become a reasonable way to understand language production and expressions. We can employ space builder words to set up the relationship between different spaces and realize the expression of a new space.

\subsubsection{Access Principle}

Sweester (1996) claims that we can adopt this kind of access to comprehend some uses and non-typical characteristics of language. Actually, we can define Access Principle as Identification Principle. It assumes that expression of a construction describing certain characteristic in certain mental space can be used to access a counterpart of the element in another mental space. Suppose that there exist two semantic items "A" and "B" which are related to a certain word, B can be affirmed by naming, describing or directing to $\mathrm{A}$. And that there is certain relation between the new built space and the base space in the process of cognition. Information in base space $\mathrm{A}$ can trigger the emergence or creation of new information in space B. Given all that, the triggering of pragmatic rules can stimulate the target structure and bring about a new construction to emerge.

\subsubsection{Domain Mapping}

Here we make a conclusion in a nutshell about domain mapping, namely elements in a certain space make are available to their counterpart in other mental spaces, and some mapping relationships are being constructed between these two mental spaces. It is therefore reasonable to infer that the mapping is a set of correspondences. We can regard domain mapping as one of the discourse mechanisms for it provides speakers available constructions for construing and neo-analysis. In the cognitive process of discourse and communication, there exist mainly three sorts of mapping: projection mapping, schema mapping and pragmatic function mapping. 


\section{Cognitive Analysis of the Non-Past Uses of Simple Past Tense}

The usages of the simple past tense are grouped into two kinds: one is the typical usage and the other is the non-typical usage. The typical usages of the simple past tense include the state past and the event past, while its non-typical usages mainly refer to the counterfactual past, the indirect speech and the past used in pragmatic softener. As far as its non-typical usages concerned, much research might be inclined to employ metaphorical character of language or distance between addresser and addressee, however, few studies uncover the main cognitive mechanisms. On the contrary, the mental space theory provides a powerful explanation and can establish a theoretical base to these non-typical usages. The configuration of mental space can be adopted to elaborate the usages of counterfactual past, indirect speech and pragmatic softener.

\subsection{Mental Space Configuration in the Counterfactual Past}

The counterfactual past in grammar is described as the subjunctive mood in which the past tense does not concern what happened before the speech time, but a kind of means that expresses the desire or hypothetical thoughts of speakers. The past tense markers can be well elaborated under the guidance of the mental space framework.

\subsubsection{Origin and Uses of the Counterfactual Past}

Originally, the simple past tense is considered to be a kind of past time marker, and similarly it is used in the counterfactual facts with its present or future interpretation. The past tense used in the counterfactual past is restricted to some specific contexts. According to previous studies, counterfactual facts are classified into the following types: if-conditions, expressions of hopes or wishes, suppositions and suggestions. Some examples in the following will be listed.

If-conditions

(1) If I studied harder, I would pass the exam.

(2) If I knew his new address, I could tell you.

(3) If I were you, I would not let out the secret.

(4) If she had time, she could come to accompany you.

Expressions of wishes

(5) I wish I remembered her address.

(6) I wish you stopped asking silly questions.

(7) I wish you had written to her.

(8) She wishes she could fly like a bird in the sky.

Suggestions and others

(9) I suggested that we should send them go out early.

(10) They propose that we accept the proposal as soon as possible.

(11) It's time that the government took action.

(12) Suppose your boyfriend came to see you this month.

(13) She acts as if she knew me very well.

(14) It is surprising that you should be so foolish.

We list some examples about different uses of counterfactual facts above. What is common is that these examples all express speakers' ideas and thoughts which are contradictory with the reality event. Some sentences express multiple events while some represent a single event. However, these examples do not convey the idea that things happened before the speech time. The academic circle all agree that there are three kinds of past usages in counterfactual facts, that is, expressing the counterfactual mood with past fact, conveying the counterfactual with recent facts and being supposed to express future facts.

\subsubsection{Types of the Counterfactual Past from Mental Space Perspective}

We employ the mental space perspective to explore the usages of counterfactual past in the simple past tense, including mental space configuration in If-condition, mental space configuration in expressions of wishes and mental space configuration in other counterfactual past.

\section{Mental Space Configuration in If-Condition}

In the If-condition clause, expressing the counterfactual past is one of the most popular constructions. And it 
is called the characteristic of the subjunctive mood by the academic circle. Three kinds of tense usages in if-condition are consistently proposed, including the present facts contrary to hypothesis, the past facts contrary to hypothesis and the future facts contrary to hypothesis. Under these conditions of the context and syntax, the simple past tense marker is no longer addressed to what happened before the speaker's speech time or event, but mainly expressing suggestion, wishes, hopes or hypothesis that are contrary to the speaker's reality. Mental space theory conducts the information packing of thoughts and speech of the speaker, which partly reflects the cognitive mechanisms that the simple past tense operates during the processing of the constructional emergence. Fauconnier (1997) [7] holds that grammar embodies a centralized reflection about cognitive ability and human thoughts and plays an crucial role in constructing meaning of language. However, the subjunctive mood is employed to convey the hypothetical meaning and non-facts verb forms. We propose that the subjunctive mood can contain two mental spaces, that is, the reality space and the hypothetical space. More often than not, there is no corresponding element in the hypothetical space, but we can mark them in detail or clearly in reality space. The approach adopting to explore counterfactuals is completely compatible with the statement that the temporal distance often stretches into realizing non-reality or non-probability. This approach also fits for the characteristics of space partitioning and accessibility. Let us take example (15) to elaborate in detail:

(15) If she had time, she would go with you

In the example (15), "if" acts as the space builder word and construes a hypothetical space M describing Past which is closely connected with V-POINT. And it like wise shares the characteristics with the FOCUS. Space M is considered to be counterfactual to a great degree in that it has no space called future in a past form. Due to the function of mental space configuration, the V-POINT effectively links with the new built space M. Therefore, a new indication space $M$ is being constructed from the base in this way. We can claim that a new predication space is set up by means of the starting point of $M$, which indicates the reality "she had time". The focus changes from the base space to the new built space. The perspectives of speakers and readers vary accordingly. The past tense in such example (15) indicates that the counterfactual fact and the present or the future facts are essentially discrepancy between them. The new built space is regarded as a hypothetical space because there is no distance preventing in it, namely "she" and "go with you". As a matter of fact, the past form of "had" shows that this is impossible, thus bringing about certain inconsistency between a hypothetical utterance and the reality.

\section{Mental Space Configuration in Expressions of Wishes}

Expressions of wishes can also used in other counterfactual pasts because most expressions of wishes did not come true. We adopt the mental space to address the wish expression taking the following example.

(16) I wish I won the lottery.

There exist two spaces in the example (16), which are the reality space and the wish space. The reality space is called space $R$ and the wish space is termed space $M$. On the basis of the space $R$, the new built space $M$ is the new focus space that can be set up by means of the space builder "wish". The focus of whole construction is the past space $M$ that can be acted as a reality enhancer. We use "A" stands for "I" and "B" stands for the event "won the lottery". "A" and "B" proportionate in the wish space. The simple past tense in the wish expressions embodies a centralized reflection between epistemic distance and its neighboring space. This usage is so common in the counterfactual past and reflects from the base to focus according to the regular way. Fillmore (1990) [10] pointed out that the wishing expressions sharing with the conditional forms indicate that the speakers pay high attention to the counterfactual event or state through a positively cognitive manner.

\section{Mental Space Configuration in the Clause for Counterfactual Past}

There are many uses and kinds for counterfactual past which act as different sense markers. On the basis of the needs of expression, this tense are indirectly used in the main clause and subordinate clause. There are times that more counterfactual past are operated in certain clause. Some counterfactual past are employed to indicate other situations using the simple past tense, in addition to the wish expression, if-condition and suggestion past. We list the following examples to elaborate.

(17) It's high time that they returned their motherland.

(18) Suppose your boy friend left you one day.

The examples of (17) and (18) are special usages in the counterfactual past. Such kind of construction does not present specific tense requirement or grammatical limitations. As a matter of fact, this construction represents a kind of hypothesis which lies at the opposite of reality. "Suppose" in the example (18) is used as conjunction which functions as the space builder word constructing a hypothetical space for speakers or hearers. 
This hypothetical information provides the ma kind of unreal reality. The suppose space $\mathrm{M}$ is based on the reality space R. And likewise the base space is regarded as the focus or the V-point of this construction. But in the suppose space $\mathrm{M}$ is a future hypothetical situation indicating that your boy friend will leave you one day. In the example (18), "left" is the past form of leave, expressing a kind of counterfactual past, which does not give evidence of what happens before the speech time. "Suppose" is the key to construct multiple mental spaces because different spaces are being built during the process of dealing with each space element. And the relationship between two spaces is gradually constructing through the space builder words and the mapping rules. This reveals that language constructing is the outcome of human thinking diversity and extension.

\subsection{Pragmatic Softeners of the Simple Past Tense}

The simple past tense is usually employed to refer to an event or a state that occurred before the utterance time, which is commonly considered as time marker. However, there are some untypical usages in the simple past tense the past tense, like euphemism or pragmatic softeners. The simple past in euphemism or pragmatic softeners plays a crucial pragmatic function and it contributes to speakers to express their politeness and is a useful vehicle for speakers to achieve the success of social communication.

\subsubsection{Connotation of Euphemism}

A euphemism is a polite word or expression that is used to refer to things that people may find upsetting or embarrassing to talk about, for example reverence, fear, shame or discomfort. A euphemism expression likewise is generated by phonetic, semantic and grammatical rules. The main reasons why cause euphemism to occur are behavioral psychological factors function. The motivation to seek out and consume rewards has evolutionarily been driven by the urge to fulfill physiological needs. Therefore, the experience of happiness and the achievement of a speaker's or hearer's interests are closely interrelated with the expression of euphemism. So essentially, the euphemism expression can bring about people's happiness and interests and to a great degree avoid people's suffering or sorrows. In another word, looking for respect or happiness and avoid hate or embarrassment are main motivation of euphemism expression.

On the whole, euphemism possesses the following features, such as the prototype feature, accompanying feature, systematic feature, superseding feature, updating feature, regional feature and so on. In terms of meaning, euphemism shares with edging-out feature. So far as the use, euphemism can be largely acceptable, context-dependent, multi-purposed and gradational-purposed. The functions of euphemisms can be accomplished by means of letting the hearers form the vagueness in construing the conceptual meaning. What the communicative vagueness of language shares with the functions of beatifying vagueness, distance vagueness and attenuating vagueness. The beautifying vagueness primarily refers to those euphemisms occur employing hyperbole expressions, and what the euphemized subjects are derived largely from humble jobs and inferior goods or services. The distance vagueness directly pays attention to those euphemisms that are constructed using the deictic functions. A great many of relations can be construed metaphorically using the spatial concept. The attenuating vagueness is to use euphemism to attenuate the pain, antipathy, discomfort brought about by blunt expressions.

\subsubsection{The Simple Past Tense Functions as Pragmatic Softeners}

The Simple Past Tense functioning as pragmatic softeners becomes powerful device saving both speakers' face in daily conversation. We will give the following examples to have a discussion.

(19) She wants to ask you if you could finish the task on time.

(20) She wanted to ask you if you could finish the task on time.

Both of the examples (19) and (20) are employed to ask for a request, but comparatively speaking, the expression in present tense is slightly direct and impolite compared with the past tense. The past tense in the example (20) is used to emphasize volition or mental state and indicates the tentative attitude of the speaker. This expression makes speakers or hearers feel more favorable or pleasant than in (19). The expressions for a request in the past tense are main strategy for politeness in the event of utterance. The request expressed in the example (20) seems to be more experimental and at the same time leaves much more chance for the addressee to think about accepting or rejecting. Luckily, mental space theory provides a reasonable explanation about how it can be operated mutually. The characters of Space M can be optimized to Space R. As a consequence, the past form of "want" is used to be a formal request, which can largely convey the interpersonal distance and to some extent extenuate the request of speakers. This usage can be dominated in the present domain, however, which does not 
fully mean its counterfactual. And essentially the relevant characters in the past domain make full use of the space R. To summarize, such request is projected onto the past domain and it similarly goes into the reality domain because the hearers can make an inference and optimization. There exists certain closely relationship between the function of the past tense and politeness or counterfactual facts in communication contexts.

The example in the following will be given to make comprehensive explanation about pragmatic softener from the perspective of mental space theory. The simple past tense used as pragmatic softener expresses a present hope and a way of expressing respect.

(21) I hoped you could give some help to children and families in need.

In the example (21), the space builder word should be "hope". And it can build up two spaces, namely the reality space and the hope space. The reality space is that I do not know whether you are willing to help children and families in need or not. But the hope space is that you could give children and families in need some help. The past form "hope" does not convey what happened in the past. On the contrary, it only refers to a present hope that expresses politeness to others. At the same time it acts as a way of expressing respect to others. Generally speaking, the simple past tense which functions as pragmatic softener is a kind of skill of language constructing or pragmatic function of language operating. The approach that the past tense adopts reflects the personal distance which relates to the mental distance of speakers or hearers.

\subsection{Mental Space Configuration Embodies in Indirect Speech}

It is widely believed that indirect speech, also called reported speech or indirect discourse, is a means of expressing the content of statements, questions or other utterances, without quoting them explicitly as is done in direct speech. In indirect speech, the simple past tense likewise is popularly employed, but it does not completely represent the past event or state. Therefore, we adopted the mental space theory to be addressed to the simple past tense of the typical uses and some untypical uses.

\section{The Analysis of Mental Space in Indirect Speech}

The Generative Grammar attempts to employ the syntactic rule of sequence to explain the changes of tense. However, there is no convincing explanation to discuss the essence of "sequences of tenses". According to Comire's statement (1985) [3], if the main clause verb is a past tense, the tense of the subordinate clause will shift back one step into the past tense of the main clause. There is usually one basic tense in one passage influencing tense choice or other peripheral tense. It demands that the present tense is followed by the present tense, and the past tense is followed by the past tense. As a consequence, the past tense is employed if the reporting verb is in the past tense form.

(22) A boy said, "he comes from Shanghai".

In the example (22), we can change into the indirect speech, that is, "A boy said he came from Shanghai". The word "lived" does not indicate that the boy only came from Shanghai at a past time. The information of this sentence also refers to that he is from Shanghai. That is to say, the simple past tense does not refer to a past event. It is obvious that the example (22) is much more convincing in that it conveys a fact. As far as indirect speech is concerned, it is just a reporting event. There are some divergences in the event of reporting and it is not easy to tell from their liability of the reporting event in the indirect speech. Cognitive linguists consider the tense change in indirect speech to be the metaphorical extension of distance in time domain. In the example (22), Space M' is the speaker's perception of reality. Space R is constructed by default and it likewise is the parent space of space M. Space M is the past space built up by the space builder word "said", and similarly Space M is in conformity with Space R. Space M' is derived from the parent space M. From the perspective of mental space theory, the report space is the speaker's perception of reality. But space $\mathrm{R}$ is the parent space or the focus or the v-point of space M and space M'. However, in most cases, the tense in the main clause seems unchanged even though the reporting verb is in the past tense form in the examples (23) and (24):

(23) Tom said that the love story is true.

(24) Mary said she feels guilty for me.

Example (23) and (24) are mixed uses of tense in reporting language. The expression "the love story is true" is still legally acceptable and it agrees with the time of speech time. This shows that the reality space and the saying space are the same. So a new space has been built, space M' stands for the present space or the truth space. And the present tense in indirect speech suggests that the speaker agrees with the old saying fully and it is 
still verified in the event of utterance. However, the past tense indicates that the speaker is suspicious about saying, or at least, need to make the verification of the statement.

\section{Conclusion}

The basic meaning of the simple past tense is employed to represent an event or state at some point or period prior to the moment of speaking. The relationship between the event time and the reference time, shares with priority, posterity and simultaneity. The simple past tense is not always used to indicate an objective time distance. However, it likewise can be used in most cases to express the counterfactual events or functions as pragmatic softeners or used in the reporting speech. In terms of the different uses, we adopt the mental space theory to explore these usages. The event does not take place at all at the reference time, that is to say, it is unreal or hypothetical, and even more imaginary. The application of psychological distance makes the expression more visual. On the whole, the past time and the reference time are closely associated mentally. The elements in the hypothetical space have their access to the reality space. Mental space provides us a powerful explanation to the non-past uses of the simple past tense.

\section{References}

[1] Quirk, R. (1985) A Comprehensive Grammar of the English Language. Longman Group Limited, London.

[2] Taylor, J.R. (2001) Linguistic Categorization: Prototypes in Linguistic Theory. Foreign Language Teaching and Research Press, Beijing

[3] Comire (1985) Tense. Cambridge University Press, Cambridge.

[4] Leech, G. (1987) Meaning and the English Verb. Longman Group Limited, London.

[5] Langacker, R.W. (2004) Foundations of Cognitive Grammar, Volume 1: Theoretical Prerequisites. Peking University Press, Beijing.

[6] Sweetser, E. (1990) From Etymology to Pragmatics: Metaphorical and Cultural Aspects of Semantic Structure. Cambridge University Press, Cambridge.

[7] Fauconnier, G. (1997) Mappings in Thought and Language. Cambridge Press, New York.

[8] Dinsmore, J. (1991) Partitioned Representations. Kluwer Academic Publishers, Dordrecht.

[9] Cutter (1994) Time \& Tense in Narratives \& Everyday Language. University of California, San Diego.

[10] Fillmore, C. (1990) Epistemic Stance and Grammatical Form in English Conditional Sentences. The 26th Regional Meeting of the Chicago Linguistic Society, 1, 137-161.

\section{Submit or recommend next manuscript to SCIRP and we will provide best service for you:}

Accepting pre-submission inquiries through Email, Facebook, LinkedIn, Twitter, etc.

A wide selection of journals (inclusive of 9 subjects, more than 200 journals)

Providing 24-hour high-quality service

User-friendly online submission system

Fair and swift peer-review system

Efficient typesetting and proofreading procedure

Display of the result of downloads and visits, as well as the number of cited articles

Maximum dissemination of your research work

Submit your manuscript at: http://papersubmission.scirp.org/ 